\title{
Expression of Cyclin D1 in Oral Squamous Cell Carcinoma
}

\section{Malak Abdulrahman Seid Ahmed ${ }^{1}$, Nazik Omer ${ }^{2}$, Ahmed M. Suliman², and Mona Ellaithi}

${ }^{1}$ Faculty of Medical Laboratory sciences, Al-Neelain University, Khartoum, Sudan

${ }^{2}$ Department of oral and maxillofacial surgery, division of oral Pathology, Faculty of Dentistry, University of Khartoum, Sudan

ORCID:

Mona Ellaithi: https://orcid.org/0000-0002-8380-0227

Corresponding Author: Mona Ellaithi; email:

Ellaithi_mona@gmail.com

Received 14 August 2021

Accepted 16 November 2021

Published 31 December 2021

Production and Hosting by

Knowledge E

(c) Malak Abdulrahman Seid Ahmed et al.. This article is distributed under the terms of the Creative Commons

Attribution License, which permits unrestricted use and redistribution provided that the original author and source are credited.

Editor-in-Chief:

Prof. Mohammad A. M. Ibnouf

\section{Abstract}

Background: Cyclin D1 expression regulates normal cell cycle. Its deregulation or overexpression may cause disruption in the normal cell cycle control and lead to cancer progression. In this study, we aimed to study the expression of cyclin D1 in oral squamous cell carcinoma (OSCC) and find its association with the different grades of oral tumors, if any.

Methods: This cross-sectional study included 40 formalin-fixed paraffin-embedded tissue blocks specimens of OSCC with variable grades. The expression of cyclin D1 was evaluated through immunohistochemical (IHC) staining.

Results: A total of 40 ( 9 female and 31 male) samples were included, with a maleto-female ratio of 3.4:1. The age ranged between 25 and 90 years with an average age of 65.5 years. Twenty-five (62.5\%) samples were diagnosed as well-differentiated squamous cell carcinoma (WDSCC) and fifteen (37.5\%) as poorly differentiated squamous cell carcinoma (PDSCC). No cases of moderately differentiated squamous carcinoma were included in the study. The expression of cyclin D1 was detected in the cases of WDSCC and a lesser expression was seen in the PDSCC with a $P$-value of 0.0003 , OR 1581 and $95 \% \mathrm{Cl}$ (29.8239 to 83810.7113$)$.

Conclusion: Cyclin D1 is expressed in OSCC and stronger expression was detected in WDSCC.

Keywords: Cyclin D1, oral squamous cell carcinoma (OSCC), Toombak, Sudanese oral cancer, immunohistochemistry

\section{Introduction}

Cyclin-dependent kinases (CDKs) are a family of serine/threonine kinases controlling progression through the cell cycle [1]. The cyclin-CDKs direct a linear progression of actions that transfer cells from a resting state (GO) to cell division (M). If any abnormalities occur in any of these phases, CDKs start a signal that triggers a cell cycle arrest until the issue is resolved. There are 11 cyclins found in human cells with many having subfamily members (e.g., D-type cyclin D1, D2, and D3) [2]. If a mutation arises, it 
affects the cyclin function and can lead to derailed cellular proliferation and thus cancer. Cyclin D1 overexpression is important for the development and progression of several cancers including breast, esophagus, bladder, and lung [3-10]. Different studies have reported increased cyclin D1 in oral squamous cell carcinoma (OSCC) [11-15]. However, the association of cyclin D1 with pathological grading was inconclusive. Therefore, this study aimed to evaluate the expression of cyclin D1 in OSCC in Sudanese patients and its potential association with cancer grade.

\section{Materials and Methods}

This cross-sectional study included a total of 40 formalin-fixed, paraffin-embedded tissue samples histopathologically diagnosed with different grades of squamous cell carcinoma of the oral cavity. The samples were recruited from the upper aerodigestive tract (UADT) biobank in collaboration with the pathology department, Khartoum University during the years 2014-2016.

Then, the immunohistochemical (IHC) staining was carried out using the indirect streptavidin-biotin method. In the beginning, sections from each tissue block were cut to a thickness of $3 \mu \mathrm{m}$ by rotary microtome, mounted in positively charged slides then de-paraffinized in an oven for 30 min and treated in xylene. Rehydration was carried out in graded ethyl alcohol (100\%, 90\%, 70\%, 50\%, respectively) and transferred into distilled water for 2 min. Antigen retrieval was performed by using a water-bath with a citrate buffer $(\mathrm{pH}$ 6.8). Then, slides were incubated for $10 \mathrm{~min}$ in $0.3 \%$ hydrogen peroxide to block endogenous peroxidase activity. The slides were then treated with anti-cyclin D1 primary antibody for 20 min and washed in phosphate buffer saline $\mathrm{pH}$ 7.4). After that, the slides were treated with biotinylated secondary antibody for 20 min and then incubated in streptavidin-horseradish peroxidase for $15 \mathrm{~min}$, washed in phosphate buffer saline ( $\mathrm{pH}$ 7.4), incubated in 3-3 diaminobenzidine tetrahydrochloride (DAB) substrate solution for $7 \mathrm{~min}$, and then washed in a running tap water. The slides were counterstained in Mayer's hematoxylin stain for $1 \mathrm{~min}$, dehydrated in graded alcohol, cleared with xylene, and finally mounted in DPX mounting media [16]. All quality control measures were adopted; positive and negative control slides were used during IHC staining.

Detection of more than five cells with brown nucleus per one field is considered a positive result. Data analysis was done using the SPSS v.16. The mean frequency and Chi-square test values were calculated and $P$-value $<0.05$ was considered significant. 


\section{Results}

The study included 9 female and 31 male samples with a male-to-female ratio of 3.4:1. The age ranged between 25 and 90 years with an average age of 65.5 years. Twenty five $(62.5 \%)$ samples were diagnosed as well-differentiated squamous cell carcinoma (WDSCC) and 15 (37.5\%) as poorly differentiated squamous cell carcinoma (PDSCC) (Table 1). There was no moderately differentiated squamous cell carcinoma case at the time of the study. The expression of cyclin D1 was strongly detected in the cases of WDSCC, while a lesser expression was seen in the cases of PDSCC. Cyclin D1 expression showed a $p$-value of 0.0003 , OR 1581, and 95\% Cl (29.8239 to 83810.7113) (Table 2).

\section{Discussion}

Cyclin D1 expression occurs during the $\mathrm{G} 1$ phase of the cell cycle. Its fundamental role is to integrate extracellular growth factor signals with the cell cycle regulatory mechanism [17-19]. Deregulation which leads to overexpression of cyclin D1 may shorten the G1 phase, increase cell proliferation, and reduce the need to growth factors [20], which in turn might result in an accumulation of unrepaired DNA mutations resulting in loss of cell cycle control and thus tumor formation [21].

In the present study, the average age of the patients was 65.5 years, which is the common age in patients diagnosed with oral cancer. Oral cancer develops mainly between the sixth and the seventh decades of life and incidence in younger people (aged $<40$ years) is infrequent [22 -28]. In the Arab countries, including Sudan, oral cancer patients were mostly in their $50 \mathrm{~s}$ and $60 \mathrm{~s}$, and the rate at a younger age was reported [29].

In this study, males were three times more affected with OSCC than females, an observation reported by many investigators [30-35], including Sudanese scientists who had attributed males' increased exposure to their frequent use of Toombak $[36,31,37$.

Furthermore, it is known that SCC constitutes $90 \%$ of the oral cancer [38, 39] and that WDSCC was more common than other types, thus our findings were expected.

The study showed overexpression of cyclin D1 in $62.5 \%$ of cases examined. This was comparable with previous studies $[40,41,42]$ who reported an overexpression in oral SCC in $68 \%, 63 \%$, and $70.7 \%$ of the cases, respectively.

Here, and based on the grade of OSCC, cyclin D1 expression was mainly detected in WDSCC and a lesser expression in PDSCC. This observation is different from what was reported by Mate et al. in 1996 [43] who found cyclin D1 expression significantly 
increases with the increase in differentiation of OSCC, however, similar to Saawarn et al., who showed lesser expression with the advanced grades [44]. The diverse technical and biological reasons play a role in cyclin D1 expression which is why the role of cyclin D1 in cancer initiation and progression appears to be complex [45]. This could explain the contradicting prognostic significance of cyclin D1 [46-49].

On the other hand, HPV infection remains to be the best prognostic factor for head and neck cancers. This is because patients diagnosed with HPV infection have better clinical outcomes than other patients who are not [50]. This might reflect the fact that the cyclin D1 is rarely amplified in HPV-infected tumors [51, 52]. Although we do not have information on HPV infection on the studied samples, a previous study on Sudanese patients diagnosed with upper aerodigestive tract cancers showed 26 (17.3\%) out of 150 patients were positive for HPV [53].

In conclusion, cyclin D1 can be used in the diagnosis of OSCC and its relationship with tumor progression needs to be further investigated.

\section{Acknowledgements}

"The samples reported in this article were recruited from the UADT cancers (use the full name) biobank in collaboration with the Department of oral and maxillofacial surgery, division of oral Pathology, Faculty of Dentistry, University of Khartoum which provided the paraffin embedded oral tissue samples. The establishment of UADT biobank was support of a Return Grant obtained within the framework of the International Agency for Research on Cancer (IARC) Research Training and Fellowship Programme." The UADT biobank was established from this fund.

\section{Ethical Consideration}

This project was approved by the National Research Ethical Review Committee Health Research Council, Republic of Sudan National Ministry of Health in 2014. All samples are part of the UADT cancer biobank. Informed consent was signed by all study participants.

\section{Competing Interests}

The authors declare that they have no competing interests. 
TABLE 1: The different grades of oral cancer SCC.

\begin{tabular}{l|lcl} 
Oral cancer grade & $\begin{array}{l}\text { Number } \\
\text { patients }\end{array}$ & $\begin{array}{c}\text { of diagnosed Percentage } \\
\text { (\%) }\end{array}$ \\
\hline WDSCC & 25 & 62.5 \\
\hline PDSCC & 15 & 37.5 \\
\hline Total & $\mathbf{4 0}$ & 100
\end{tabular}

TABLE 2: The association of cyclin D1 and OC histopathology grade.

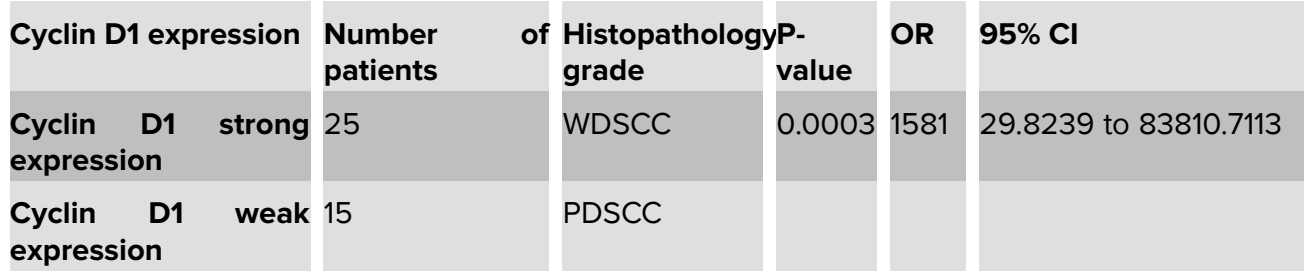

\section{Availability of Data and Material}

Data published in this project will be available upon request; however, patients' identity will be blocked in order to protect the study participants.

\section{Funding}

\section{No funding was received.}

\section{References}

[1] Malumbres, M. and Barbacid, M. (2005). Mammalian cyclin-dependent kinases. Trends in Biochemical Sciences, vol. 30, no. 11, pp. 630-634.

[2] Casimiro, M. C., Crosariol, M., Loro, E., et al. (2012). Cyclins and cell cycle control in cancer and disease. Genes \& Cancer, vol. 3, no. 11-12, pp. 649-657.

[3] Motokura, T. and Arnold, A. (1993). Cyclin D and oncogenesis. Current Opinion in Genetics and Development, vol. 3, no. 1, pp. 5-10.

[4] Weinstat-Saslow, D., Merino, M. J., Manrow, R. E., et al. (1995). Overexpression of cyclin D mRNA distinguishes invasive and in situ breast carcinomas from nonmalignant lesions. Nature Medicine, vol. 1, no. 12, pp. 1257-1260.

[5] Hall, M. and Peters, G. (1996). Genetic alterations of cyclins, cyclin-dependent kinases, and Cdk inhibitors in human cancer. Advances in Cancer Research, vol. 68, pp. 67-108.

[6] Gillett, C., Smith, P., Gregory, W., et al. (1996). Cyclin D1 and prognosis in human breast cancer. International Journal of Cancer, vol. 69, no. 2, pp. 92-99. 
[7] Sutherland, R. L. and Musgrove, E. A. (2002). Cyclin D1 and mammary carcinoma: new insights from transgenic mouse models. Breast Cancer Research, vol. 4, no. 1, pp. 14-17.

[8] Vermeulen, K., Van Bockstaele, D. R., and Berneman, Z. N. (2003). The cell cycle: a review of regulation, deregulation and therapeutic targets in cancer. Cell Proliferation, vol. 36, no. 3, pp. 131-149.

[9] Knudsen, K. E., Diehl, J. A., Haiman, C. A., et al. (2006). Cyclin D1: polymorphism, aberrant splicing and cancer risk. Oncogene, vol. 25, no. 11, pp. 1620-1628.

[10] Yamamoto, M., Tamakawa, S., Yoshie, M., et al. (2006). Neoplastic hepatocyte growth associated with cyclin D1 redistribution from the cytoplasm to the nucleus in mouse hepatocarcinogenesis. Molecular Carcinogenesis, vol. 45, no. 12, pp. 901-913.

[11] Miyamoto, R., Uzawa, N., Nagaoka, S., et al. (2003). Prognostic significance of cyclin D1 amplification and overexpression in oral squamous cell carcinoma. Oral Oncology, vol. 39, no. 6 , pp. 610-618.

[12] Das, S. N., Khare, P., Singh, M. K., et al. (2011). Correlation of cyclin D1 expression with aggressive DNA pattern in patients with tobacco-related intraoral squamous cell carcinoma. Indian Journal of Medical Research, vol. 133, no. 4, pp. 381-386.

[13] Shenoy, A. M. (2011). Cyclin D1 over expression as a prognostic factor in patients with tobacco-related intraoral squamous cell carcinoma. Indian Journal of Medical Research, vol. 133, no. 4, pp. 364-365.

[14] Swaminathan, U., Joshua, E., Umadevi, K., et al. (2012). Expression of p53 and Cyclin D1 in oral squamous cell carcinoma and normal mucosa: an immunohistochemical study. Journal of Oral and Maxillofacial Pathology, vol. 16, no. 2, pp. 172-177.

[15] Lin, R. J., Lubpairee, T., Liu, K. Y., et al. (2013). Cyclin D1 overexpression is associated with poor prognosis in oropharyngeal cancer. Journal of Otolaryngology - Head \& Neck Surgery, vol. 42, no. 1, pp. 1-7.

[16] Bancroft, J. D., Layton, C., and Suvarna, S. K. (2013). Bancrofts Theory and Practice of Histological Techniques ( $7^{\text {th }}$ ed.). Churchill Livingstone: Elsevier.

[17] Todd, R., Hinds, P. W., Munger, K., et al. (2002). Cell cycle dysregulation in oral cancer. Critical Reviews in Oral Biology \& Medicine, vol. 13, no. 1, pp. 51-61.

[18] Fu, M., Wang, C., Li, Z., et al. (2004). Minireview: Cyclin D1: normal and abnormal functions. Endocrinology, vol. 145, no. 12, pp. 5439-5447.

[19] Assoian, R. K. and Klein, E. A. (2008). Growth control by intracellular tension and extracellular stiffness. Trends in Cell Biology, vol. 18, no. 7, pp. 347-352.

[20] Donnellen, R. and Chetty, R. (1998). Cyclin D1 and human neoplasia. Journal of Clinical Pathology, vol. 51, no. 1, pp. 1-7. 
[21] Alao, J. P. (2007). The regulation of cyclin D1 degradation: roles in cancer development and the potential for therapeutic invention. Molecular Cancer, vol. 6, no. 1, p. 24

[22] Shiboski, C. H., Schmidt, B. L., and Jordan, R. C. (2007). Racial disparity in stage at diagnosis and survival among adults with oral cancer in the US. Community Dentistry and Oral Epidemiology, vol. 35, no. 3, pp. 233-240.

[23] Zini, A., Czerninski, R., and Sgan-Cohen, H. D. (2010). Oral cancer over four decades: epidemiology, trends, histology, and survival by anatomical sites. Journal of Oral Pathology \& Medicine, vol. 39, no. 4, pp. 299-305.

[24] Johnson, N. W., Jayasekara, P., and Amarasinghe, A. A. (2011). Squamous cell carcinoma and precursor lesions of the oral cavity: epidemiology and aetiology. Periodontology 2000, vol. 57, no. 1, pp. 19-37.

[25] Marocchio, L. S., Lima, J., Sperandio, F. F., et al. (2010). Oral squamous cell carcinoma: an analysis of 1,564 cases showing advances in early detection. Journal of Oral Science, vol. 52, no. 2, pp. 267-273.

[26] Sarkaria, J. N. and Harari, P. M. (1994). Oral tongue cancer in young adults less than 40 years of age: rationale for aggressive therapy. Head \& Neck, vol. 16, no. 2, pp. 107-111.

[27] Chitapanarux, I., Lorvidhaya, V., Sittitrai, P., et al. (2006). Oral cavity cancers at a young age: analysis of patient, tumor and treatment characteristics in Chiang Mai University Hospital. Oral Oncology, vol. 42, no. 1, pp. 83-88.

[28] Llewellyn, C., Johnson, N. W., and Warnakulasuriya, K. (2004). Risk factors for oral cancer in newly diagnosed patients aged 45 years and younger: a case-control study in Southern England. Journal of Oral Pathology \& Medicine, vol. 33, no. 9, pp. $525-532$.

[29] Al-Jaber, A., Al-Nasser, L., and El-Metwally, A. (2016). Epidemiology of oral cancer in Arab countries. Saudi Medical Journal, vol. 37, no. 3, pp. 249-255.

[30] Elbeshir, E., Abeen, H., Idris, A., et al. (1989). Snuff dipping and oral cancer in Sudan: a retrospective study. British Journal of Oral and Maxillofacial Surgery, vol. 27, no. 3, pp. 243-248.

[31] Idris, A., Ahmed, H., Mukhtar, B., et al. (1995). Descriptive epidemiology of oral neoplasms in sudan 1970-1985 and the role of toombak. International Journal of Cancer, vol. 61, no. 2, pp. 155-158.

[32] Ahmed, H. G. (2013). Aetiology of oral cancer in the Sudan. Journal of Oral \& Maxillofacial Research, vol. 4, no. 2, p. e3. 
[33] Osman, T. A., Satti, A. A., Bøe, O. E., et al. (2010). Pattern of malignant tumors registered at a referral oral and maxillofacial hospital in Sudan during 2006 and 2007. Journal of Cancer Research and Therapeutics, vol. 6, no. 4, pp. 473-477.

[34] Pednekar, M. S., Gupta, P. C., Yeole, B. B., et al. (2011). Association of tobacco habits, including bidi smoking, with overall and site-specific cancer incidence: results from the Mumbai cohort study. Cancer Causes \& Control, vol. 22, no. 6, pp. 859-868.

[35] IARC Working Group on the Evaluation of Carcinogenic Risks to Humans Personal habits and indoor combustions. (2012). Volume 100E: a review of human carcinogens. IARC Monographs on the Evaluation of Carcinogenic Risks to Humans, vol. 100, Pt. E, pp. 1-538.

[36] Idris, A. M., Prokopczyk, B., and Hoffmann, D. (1994). Toombak: a major risk factor for cancer of the oral cavity in Sudan. Preventive Medicine, vol. 23, no. 6, pp. 832-839.

[37] Idris, A. M., Ibrahim, S. O., Vasstrand, E. N., et al. (1998). The Swedish snus and the Sudanese toombak: are they different? Oral Oncology, vol. 34, no. 6, pp. 558-566;

[38] Odell, E. W., Jani, P., Sherriff, M., et al. (1994). The prognostic value of individual histologic grading parameters in small lingual squamous cell carcinomas. The importance of the pattern of invasion. Cancer, vol. 74, no. 3, pp. 789-794.

[39] Montero, P. H. and Patel, S. G. (2015). Cancer of the oral cavity. Surgical Oncology Clinics of North America, vol. 24, no. 3, pp. 491-508.

[40] Choudhary, A., Kesarwani, P., Gaikwad, P., et al. (2016). Expression of cyclin D1 in oral squamous cell carcinoma and its correlation with histological differentiation: an immunohistochemical study. Journal of Indian Academy of Oral Medicine and Radiology, vol. 28, no. 2, pp. 140-144.

[41] Lam, K. Y., Irene, O. L., Yuen, A. P., et al. (2000). Cyclin D1 expression in oral squamous cell carcinomas: clinicopathological relevance and correlation with p53 expression. Journal of Oral Pathology \& Medicine, vol. 29, no. 4, pp. 167-172.

[42] Angadi, P. V. and Krishnapillai, R. (2007). Cyclin D1 expression in oral squamous cell carcinoma and verrucous carcinoma: correlation with histological differentiation. Oral Surgery, Oral Medicine, Oral Pathology, and Oral Radiology, vol. 103, no. 3, pp. 30-35.

[43] Wu, M., Putti, T. C., and Bhuiya, T. A. (2002). Comparative study in the expression of p53, EGFR, TGF- alpha, and cyclin D1 in verrucous carcinoma, verrucous hyperplasia and squamous cell carcinoma of head and neck region. Applied Immunohistochemistry \& Molecular Morphology, vol. 10, no. 4, pp. 351-356. 
[44] Saawarn, S., Astekar, M., Saawarn, N., et al. (2012). Cyclin D1 expression and its correlation with histopathological differentiation in oral squamous cell carcinoma. Scientific World Journal, vol. 2012, p. 978327.

[45] Montalto, F. I. and De Amicis, F. (2020). Cyclin D1 in cancer: a molecular connection for cell cycle control, adhesion and invasion in tumor and stroma. Cells, vol. 9, no. 12, p. 2648.

[46] Perisanidis, C., Perisanidis, B., and Wrba, F. (2012). Evaluation of immunohistochemical expression of p53, p21, p27, cyclin D1, and Ki67 in oral and oropharyngeal squamous cell carcinoma. Journal of Oral Pathology \& Medicine, vol. 41, no. 1, pp. $40-46$.

[47] Smith, B. (2001). SGLCD. Molecular marker expression in oral and oropharyngeal squamous cell carcinoma. The Archives of Otolaryngology - Head \& Neck Surgery, vol. 127 , no. 7, pp. 780-785.

[48] Michalides, R., van Veelen, N. M., Kristel, P. M., et al. (1997). Overexpression of cyclin D1 indicates a poor prognosis in squamous cell carcinoma of the head and neck. The Archives of Otolaryngology - Head \& Neck Surgery, vol. 123, no. 5, pp. 497-502.

[49] Rasamny, J. J., Allak, A., and Krook, K. A. (2012). Cyclin D1 and FADD as biomarkers in head and neck squamous cell carcinoma. Otolaryngology-Head and Neck Surgery, vol. 146 , no. 6 , pp. 923-931.

[50] Faraji, F., Schubert, A. D., Kagohara, L. T., et al. (2018) The genome-wide molecular landscape of HPV-driven and HPV-negative head and neck squamous cell carcinoma. In B. Burtness and E. Golemis (Eds.), Molecular determinants of head and neck cancer. Current Cancer Research. Cham: Humana Press.

[51] Hermida-Prado, F., Menéndez, S. T., Albornoz-Afanasiev, P., et al. (2018). Distinctive expression and amplification of genes at 11q13 in relation to HPV status with impact on survival in head and neck cancer patients. Journal of Clinical Medicine, vol. 7, no. 12, p. 501.

[52] van Kempen, P. M., Noorlag, R., Braunius, W. W., et al. (2015). Clinical relevance of copy number profiling in oral and oropharyngeal squamous cell carcinoma. Cancer Medicine, vol. 4, no. 10, pp. 1525-1535.

[53] Mohamed, F. E., Aldayem, L. N., Hemaida, M. A., et al. (2021). Molecular detection of human papillomavirus-16 among Sudanese patients diagnosed with squamous cell carcinoma and salivary gland carcinoma. BMC Research Notes, vol. 14, no. 1, p. 56. 